\title{
Efeito antagonista de fungos predadores do gênero Arthrobotrys sobre larvas infectantes de Oesophagostomum radiatum, Cooperia punctata e Haemonchus placei*
}

\author{
Antagonistic effect of nematode-trapping fungi Arthrobotrys on infective \\ larvae of Oesophagostomum radiatum, Cooperia punctata and \\ Haemonchus placei*
}

Jackson Victor de Araújo, ${ }^{\star \star}$ Arthur Kanadani Campos, ${ }^{\star \star \star}$ Fernando Paiva, ${ }^{\star \star \star \star}$ Maria Cecília Reale Vieira Bressan ${ }^{\star \star \star \star}$

\begin{abstract}
Resumo
A pesquisa objetivou testar e comparar a capacidade predatória de fungos do gênero Arthrobotrys (dois isolados de $A$. robusta e um de A. conoides) sobre larvas infectantes de Oesophagostomum radiatum, Cooperia punctata e Haemonchus placei. Testes in vitro sobre agar-água $2 \%$ em placas de Petri e de viabilidade para predar larvas infectantes destes nematóides, após a passagem de conídios pelo trato gastrintestinal, foram realizados. Todos os isolados fúngicos foram eficazes contra larvas infectantes de $O$. radiatum $(P<0,05)$ em relação ao grupo controle sem tratamento fúngico. Todos os fungos passaram através do trato gastrintestinal dos bezerros, todavia, não foram capazes de predar mais larvas infectantes dos diversos nematóides em relação ao grupo controle sem fungos $(P>0,05)$. Estes resultados indicam que larvas infectantes de 0 . radiatum são igualmente predadas como as de $C$. punctata e H. placei por fungos do gênero Arthrobotrys e que após a passagem pelo trato gastrintestinal, os fungos do gênero Arthrobotrys apresentaram a sua capacidade predatória diminuída.
\end{abstract}

Palavras-chave: controle biológico; fungos nematófagos; fungos predadores; Arthrobotrys, nematóides; Cooperia punctata; Haemonchus placei; Oesophagostomum radiatum.

\begin{abstract}
In vitro experiments and for passage through the gastrointestinal tract of calves were performed to test two isolates of Arthrobotrys robusta and one isolate of $A$. conoides without losing the ability to entrap infective larvae of Oesophagostomum radiatum, Cooperia punctata and Haemonchus Placei were performed. The isolates of fungi were efficient against the nematodes $(P<0.05)$. All the fungi passed through the gastrointestinal tract of the calves, but they did not get to prey more infective larvae than the control group without fungi treatment $(P>0.05)$. These results demonstrate that infective $O$. radiatum larvae are preying equal to infective larvae of $C$. punctata and $H$. placei and after the passage through the gastrointestinal tract the fungi can lose the predatory capacity.
\end{abstract}

Keywords: biological control; nematophagous fungi; nematode-trapping fungi; Arthrobotrys; nematodes; Cooperia punctata; Haemonchus placei; Oesophagostomum radiatum.

\section{Introdução}

Entre os fatores que interferem no desenvolvimento da pecuária bovina, as helmintoses ocupam grande destaque, por causarem retardamento do desenvolvimento dos animais, morte e gastos excessivos com manejo, levando a uma baixa produtividade do rebanho e, conseqüentemente, a elevadas perdas econômicas. Este problema é agravado à medida que pioram as condições das pastagens, principalmente, na épo- ca da seca ou quando se verifica o aumento da concentração de animais em certas áreas, facilitando a infecção. A maioria dos animais geralmente apresenta infecção subclínica, em virtude da imunidade adquirida, tornando-se difícil quantificar os efeitos desse tipo de infecção helmíntica. Os efeitos das helmintoses sobre o rebanho bovino são mais evidentes nos animais jovens, os quais ainda não adquiriram resistência imunológica a esses agentes.

\footnotetext{
* Projeto financiado pela FAPEMIG.

** Autor de correspondência. Departamento de Veterinária, Universidade Federal de Viçosa, CEP 36571-000, Viçosa-MG, Brazil, Phone: 55 0xx 31 8991464, Fax: 55 0xx 31 8992317, E-mail: jvictor@mail.ufv.br

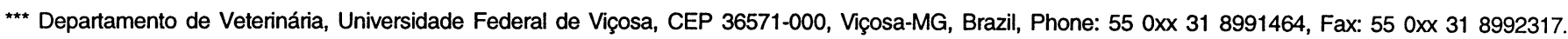
**** Instituto de Biociências, Universidade de São Paulo.
} 
Nas últimas décadas, houve uma conscientização da importância dos helmintos gastrintestinais e, em especial, dos nematóides como fatores negativos no desempenho da pecuária. Concomitantemente, houve uma revolução no desenvolvimento de compostos químicos elaborados especificamente para uso como anti-helmínticos, resultando em produtos de baixa toxicidade e amplo espectro de atividade. No entanto, os resultados da aplicação desses produtos com a finalidade de melhorar a produtividade bovina têm sido decepcionantes (Honer; Bianchin, 1987).

Atualmente, a epidemiologia dos helmintos desenvolveu uma nova visão, na qual há duas fases principais no ciclo biológico. A primeira fase é a da infecção do hospedeiro propriamente dita e a segunda refere-se à população de formas no meio ambiente do hospedeiro, a qual representa infecções futuras e que apresenta estratégias de sobrevivência e comportamento, cuja finalidade é o encontro com um novo hospedeiro. Em quase todas as infecções helmínticas estudadas, concluiu-se que a segunda fase é muito mais importante epidemiologicamente do que a primeira e que os esforços de controle devem ser concentrados nesta segunda fase. A finalidade do controle é, portanto, interromper o processo pelo qual a infecção potencial, no meio ambiente, torna-se uma infecção no hospedeiro final (Honer; Bianchin, 1987).

Até então, esse tipo de controle tem sido realizado com a aplicação estratégica de anti-helmínticos, visando a redução da contaminação das pastagens (Brunsdon, 1980).

Novas práticas de controle das nematodioses gastrintestinais de bovinos que interfiram na infestação das pastagens e na infecção parasitária dos animais, aliadas com o tratamento anti-helmíntico, poderão, no futuro, ajudar a solucionar os problemas decorrentes das verminoses. O controle biológico por meio do uso de fungos nematófagos se apresenta como uma das mais promissoras. Além disso, são os organismos antagonistas de nematóides mais pesquisados e quase todos reduzem efetivamente populações de nematóides em laboratório, possuindo eficácia comprovada em nematóides presentes na pastagem (Waller; Larsen, 1993).

Em um teste a campo realizado por Araújo et al. (1998), bezerros experimentalmente infectados com 10 mil larvas infectantes de Cooperia punctata e naturalmente infectados por helmintos gastrintestinais foram tratados com dois miIhões de conídios do isolado de $A$. robusta, por via oral, duas vezes por semana, durante quatro meses, a partir de outubro de 1995, e apresentaram, em relação aos bezerros não-tratados (controle), $53,81 \%$ de redução no OPG $(P<0,05)$ e $70,45 \%$ de redução $(P<0,05)$ no número de vermes recuperados à necrópsia dos animais traçadores, nos últimos três meses (janeiro, fevereiro e março de 1996) do experimento. No entanto, a curva de ocorrência de Oesophagostomum radiatum superou às de Cooperia e Haemonchus. Deste resultado, concluiu-se que esta espécie é menos predada por este fungo em relação às espécies dos outros dois gêneros de helmintos. Todavia, posteriores testes específicos in vitro e in vivo com Oesophagostomum são necessários para confirmar este resultado. $O$ objetivo deste trabalho foi o de testar e comparar a capacidade predatória de fungos do gênero Arthrobotrys sobre larvas infectantes de cultura pura de $O$. radiatum, bem como cultura mista de $C$. punctata e $H$. placei em ensaios in vitro e após a passagem pelo trato gastrintestinal de bezerros.

\section{Material e métodos}

Larvas infectantes (L3) de C. punctata, de H. placei e de $O$. radiatum foram obtidas de cepas puras de bezerros, experimentalmente, infectados e mantidos na Universidade de São Paulo (USP).

Panagrellus (nematóides de vida livre) mantidos em placas de Petri com meio de aveia em flocos, umedecida e amassada segundo Heintz e Pramer (1978), oriundos do Departamento de Fitopatologia da Universidade Federal de Viçosa (UFV) foram cedidos, gentilmente, pelo professor Silamar Ferraz.

Para obtenção de nematóides sem bactérias fecais e fungos, estes foram lavados dez vezes com água destilada por centrifugação a $1.000 \mathrm{rpm}$, por cinco minutos, desprezando no final de cada centrifugação o sobrenadante. Posteriormente, os nematóides foram estocados a $4^{\circ} \mathrm{C}$, por uma semana, em solução contendo $0,05 \%$ de sulfato de estreptomicina, $0,05 \%$ de cloranfenicol e $0,05 \%$ de anfotericina $B$, sendo repetido o processo de lavagem em água destilada, como descrito anteriormente.

Os nematóides foram contados, utilizando microscópio óptico (objetiva de 10x), tomando-se três alíquotas de $50 \mu \mathrm{l}$, tirando a média e extrapolando para o volume total.

Três isolados de fungos predadores do gênero Arthrobotrys foram utilizados neste experimento. Esses isolados, segundo as chaves de classificação de Cooke \& Godfrey (1964), Haard (1968) e Van Oorschot (1985), são constituídos de dois isolados de $A$. robusta (isolados $A$ e $B$ ) e um isolado de $A$. conoides (isolado $C$ ). Estes isolados foram oriundos de solo das seguintes localidades: isolado $A$, de Jaguapitã-PR; isolados B e C, de Atalaia-PR e foram obtidos pelo método do espalhamento do solo de Dunddington (1955), modificado por Santos et al. (1991).

\section{Ensaio in vitro}

Foram formados três grupos no ensaio de cada isolado fúngico e larvas infectantes de nematóides oriundos de infecções mistas (48\% de C. punctata, $32 \%$ de H. placei e $20 \%$ de O. radiatum) e de cultura pura de Oesophagostomum assim distribuídos: grupo 1, constituído de 1.000 conídios e 10.000 L3; grupo 2, 1.000 conídios; e grupo 3 (controle), 10.000 L3. O efeito antagonista dos fungos sobre os nematóides foram testados e analisados segundo procedimento descrito por Araújo et al. (1993) por 20 dias.

\section{Ensaios de passagem de conídios pelo trato gastrintestinal de bovinos e viabilidade para predar larvas infectantes}

Oito bezerros machos, mestiços holandês $\mathrm{x}$ zebu, com idade entre oito e dez meses e estabulados, foram divididos, aleatoriamente, em quatro grupos de dois animais: grupos 4, 5, 6 e 7 (controle).

Cada um dos animais dos grupos 4, 5 e 6 recebeu, por via oral, $20 \times 10^{6}$ conídios. Os animais dos grupos 4, 5 e 6 receberam conídios, respectivamente, dos isolados $\mathrm{A}$ de $A$. robusta, $\mathrm{B}$ de $A$. robusta e do isolado $\mathrm{C}$ de $A$. conoides. Os bezerros do grupo 7 (controle) não receberam conídios. Em um período anterior a cinco dias e após cinco dias da administração de 
conídios aos animais, cada um foi alimentado, diariamente, com $1 \mathrm{~kg}$ de milho triturado e $3 \mathrm{~kg}$ de capim-elefante (Pennisetum purpureum) autoclavados.

As coletas de amostras fecais de cada animal foram realizadas às $12,15,18,21,24,48,72$, e 96 horas após a administração de conídios. Destas amostras, foram retirados $2 \mathrm{~g}$ de fezes, que foram colocadas, individualmente, sobre placas de Petri, contendo ágar-água $2 \%$. Posteriormente, sobre estas fezes foram vertidas 2 mil larvas infectantes oriundas das coproculturas das infecções mistas $(33 \%$ de C. punctata, $33 \%$ de $\mathrm{H}$. placei e $33 \%$ de $\mathrm{O}$. radiatum) e 2 mil larvas infectantes de $O$. radiatum em procedimento de duplicata. Todas as placas foram mantidas à temperatura de $25^{\circ} \mathrm{C}$ e no escuro.

De cinco em cinco dias, as $L 3$ foram recuperadas das placas com o funil de Baermann, colocando-se água a $42-45^{\circ} \mathrm{C}$. Estas L3 foram contadas com o auxílio de microscópio óptico (objetiva de 10x), tomando-se a média de três repetições. Nas placas de Petri com fezes, onde foram empregadas as culturas mistas de nematóides, foi tomada a variação percentual de cada nematóide. Foram feitas análises de variância seguida por aplicação do teste de Tukey em um nível de significância de $5 \%$ para saber se houve variações entre os tratamentos.

\section{Resultados e discussão}

$\mathrm{Na}$ Tabela 1 estão representados os resultados percentuais dos testes in vitro dos diversos fungos nematófagos sobre os nematóides do dia zero até o vigésimo dia.

Tabela 1 - Variação percentual de larvas infectantes de nematóides após 20 dias de teste in vitro com os isolados fúngicos de Arthrobotrys

\begin{tabular}{|c|c|c|}
\hline Isolados fúngicos (nematóides) & Dia zero & Dia 20 \\
\hline Oesophagostomum & $20 \%$ & $21,2 \%$ \\
\hline (A. robusta) Cooperia e Haemonchus & $80 \%$ & $70,8 \%$ \\
\hline Oesophagostomum & $20 \%$ & $22,9 \%$ \\
\hline (A. robusta) Cooperia e Haemonchus & $80 \%$ & $77,1 \%$ \\
\hline Oesophagostomum & $20 \%$ & $24,0 \%$ \\
\hline (A conoides) Cooperia e Haemonchus & $80 \%$ & $76,0 \%$ \\
\hline Oesophagostomum & $20 \%$ & $24,6 \%$ \\
\hline Cooperia e Haemonchus & $80 \%$ & $75,4 \%$ \\
\hline
\end{tabular}

Não houve diferença estatisticamente significativa $(P>0,05)$ entre as variações percentuais dentro de um mesmo tratamento, ou seja, todos os nematóides foram igualmente predados.

Na maior parte do Brasil, principalmente a região central, dentre as nematodioses gastrintestinais de bovinos, os gêneros Cooperia e Haemonchus são os mais prevalentes e, geralmente, refletem a variação da contagem de ovos por grama de fezes (OPG), destacando-se, em seguida, o gênero Oesophagostomum (Araújo, 1996). De acordo com Stewart e Gasbarre (1989), o nematóide parasita gastrintestinal de bovinos $O$. radiatum é um verme de distribuição cosmopolita e em infecções experimentais de bezerros, mesmo com baixa carga parasitária, resulta em perda de peso, anemia e diarréia.

Na Figura 1 está representado o efeito antagonista de isolados de Arthrobotrys sobre larvas infectantes de $O$. radiatum. Todos os isolados de Arthrobotrys foram eficazes contra larvas infectantes de $O$. radiatum $(P<0,05)$ em relação ao grupo controle sem tratamento fúngico.

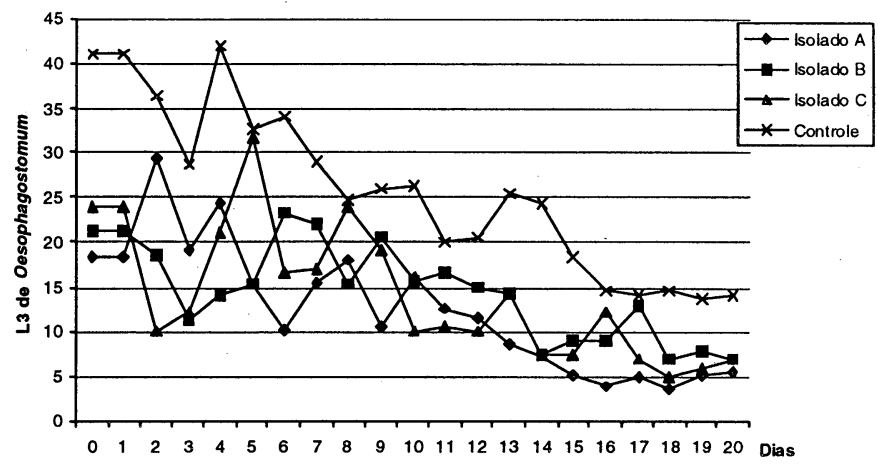

Figura 1 - Número de larvas infectantes (L3) de Oesophagostomum radiatum livres da predação de isolados de Arthrobotrys

Nestes testes in vitro, com o passar dos dias, o ágar onde foram realizadas as observações das larvas livres de predação por campo apresentou ressecamento e muitas larvas, inclusive do grupo controle, escaparam da observação. Isso também foi observado em prévios trabalhos in vitro desenvolvido por Araújo et al. (1993 e 1994).

No teste de passagem de conídios pelo trato gastrintestinal de bovinos, todos os isolados fúngicos de Arthrobotrys passaram através do trato gastrintestinal dos bezerros, confirmando trabalhos de Araújo et al. (1996 e 1999) com esses mesmos isolados fúngicos. No entanto, não foram capazes de predar mais larvas infectantes dos diversos nematóides em relação ao grupo controle sem fungos $(P>0,05)$.

Nos resultados dos ensaios realizados não houve desigualdade de eficácia de fungos do gênero Arthrobotrys sobre larvas infectantes de $O$. radiatum, $C$. punctata e $H$. placei, o que não confirma as observações de Araújo et al. (1998).

Nansen et al. (1988), ao testarem a capacidade de induzir à formação de armadilhas de $A$. oligospora por L3 de nove espécies de nematóides parasitos de animais, observaram que esta habilidade sobre L3 de C. oncophora e Ostertagia ostertagi de bovinos, C. curticei e H. contortus de ovinos e Cyathostomum de eqüinos foi maior e mais rápida do que sobre $L 3$ de $O$. dentatum e $O$. quadrispinulatum de suínos, Nematospiroides dubius de camundongos e Dictyocaulus viviparus de pulmão de bovinos. Os autores comentam que esses resultados sugerem que as espécies de nematóides com mais alta motilidade são melhores indutoras da formação de armadilhas. Todavia, todas as espécies de nematóides foram eficazmente predadas por esse isolado de $A$. oligospora em colônia previamente crescida contendo armadilhas.

Experimentos realizados por Araújo et al. (1996 e 1999) demonstraram a passagem pelo trato gastrintestinal de bezerros desses isolados testados e com eficácia comprovada sobre larvas infectantes de $H$. placei $(P<0,05)$. No presente 
experimento esta eficácia após a passagem pelo trato gastrintestinal de bezerros foi perdida. Talvez porque, possivelmente, quando da passagem, os fungos não suportaram o stress a eles submetido, ou mesmo, perderam a capacidade predatória, pois são repicados por muitos anos em condições laboratoriais. Todavia, esta última hipótese não foi confirmada pelos testes in vitro.

\section{Referências}

ARAÚJO, J.V. Interação entre larvas infectantes de Cooperia punctata e fungos predadores do gênero Arthrobotrys, caracterização de isolados de Arthrobotrys e seu uso no controle biológico de nematódeos parasitos gastrintestinais de bovinos. 1996. $110 \mathrm{f}$. Tese (Doutorado). Instituto de Ciências Biológicas - Universidade Federal de Minas Gerais.

ARAÚJO, J.V., GOMES, A.P.S., GUIMARÃES, M.P. Biological control of bovine gastrointestinal nematode parasites in southern Brazil by the nematode-trapping fungus Arthrobotrys robusta.. Rev.Bras. Parasitol. Vet., v. 7, n. 2, p. 117-122, 1998.

ARAÚJO, J.V., NETO, A.P., AZEVEDO, M.H.F. Screening parasitic nematode-trapping fungi Arthrobotrys for passage through the gastrointestinal tract of calves. Arq. Bras. Med. Vet. Zootec., v. 48, p. 543-552, 1996.

ARAÚJO, J.V., STEPHANO, M.A., SAMPAIO,W.M. Passage of nematode-trapping fungi through the gastrointestinal tract of calves. Vet. Arhiv., v. 69, p. 69-78, 1999.

ARAÚJO, J.V., SANTOS, M.A., FERRAZ, S., MAIA, A.S. Antagonistic effect of predacious Arthrobotrys fungi on infective Haemonchus placeilarvae. J. Helminthol., v. 67, p. 136-138, 1993.

. Biological control in vitro of infective Haemonchus placei larvae by predacious fungi Arthrobotrys musiformis. Arq. Bras. Med. Vet. Zootec., v. 46, p. 194-204, 1994.

BRUNSDON, R.V. Principles of helminth control. Vet. Parasitol., v. 6, p. 185-215, 1980.

\section{Conclusões}

- Larvas de Oesophagostomum radiatum são igualmente predadas como larvas de Cooperia punctata e Haemonchus placei por fungos do gênero Arthrobotrys.

- Após a passagem pelo trato gastrintestinal, os fungos do gênero Arthrobotrys apresentaram a sua capacidade predatória diminuída.

COOKE, R.C., GODFREY, B.E.S. A key of nematode-destroying fungi. Trans. Br. Mycol. Soc., v. 47, p. 61-74, 1964.

DUDDINGTON, C.L. Notes on the technique of handling predaceous fungi. Trans.Br.Mycol.Soc.v. 38, p. 97-103, 1955.

HAARD, K. Taxonomic studies on the genus Arthrobotrys Corda. Mycologia, v. 60, p. 1140-1159, 1968.

HEINTZ,C.E.; PRAMER,D. Ultrastructure of nematode-trapping fungi. J. Bacteriol., v. 110, p. 1163-1170, 1972.

HONER, M.R., BIANCHIN, I. (Ed.) Considerações básicas para um programa de controle estratégico da verminose bovina em gado de corte no Brasil.-Circulartécnica, 20. Campo Grande: EMBRAPA-CNPGC, 1987. NANSEN, P., GRONVOLD, J., HENRIKSEN, S.A., WOLSTRUP, J. Interactions between the predacious fungus Arthrobotrys oligospora and third-stage larvae of a series of animal parasitic nematodes. Vet. Parasitol., v. 26, p. 329-337, 1988.

SANTOS, M.A., FERRAZ, S., MUCHOVEJ, J.J. Detection and Ecology of nematophagous fungi from Brazilian soils. Nematol. Bras., v. 15, p. 121-134, 1991.

STEWART, T.B., GASBARRE, L.C. The veterinay importance of nodular worms (Oesophagostomum spp). Parasitology Today, v. 5, p. 209213, 1989.

VAN OORSCHOT, C.A.N. Taxonomy of the Dactylaria comples.V. A review of Arthrobotrysand allied genera. Stud. Mycol., v. 26, p. 6196, 1985.

WALLER,P.J., LARSEN, M. The role of nematophagous fungi in the biological control of nematode parasites of livestock. Int. J. Parasitol., v. 23 , p. $539-546,1993$. 